\title{
FT-IR Spectroscopy Based Evaluation of Changes in Primary Metabolites of Amsonia orientalis after In vitro 6-benzylaminopurine Treatment
}

\author{
Arda ACEMİ, Sevgi TÜRKER-KAYA*, Fazıl ÖZEN
}

\author{
Kocaeli University, Faculty of Sciences and Arts, DepartmentofBiology, Kocaeli; \\ Turkey; arda.acemi@kocaeli.edu.tr;sevgiturker@kocalli.edu.tr(*orrespondingauthor);fazil.ozen@kocaeli.edu.tr
}

\begin{abstract}
Amsonia orientalis Decne. (syn. Rhazya orientalis (Decne.) A. DC.) is only cultivated as an ornamental plant but also has a medicinal merit. The natural populations of the species were taken under conservation as per the Bern Convention by European Council. As one of the most common plant growth regulators and synthetic agricultural fertilizers, the effects of 6benzylaminopurine (BAP) at different concentrations on primary metabolites of in vitro propagated $A$. orientalis have been investigated by using Fourier transform infrared (FT-IR) spectroscopy. Among all applied concentrations, $2.0 \mathrm{mg} \mathrm{l}^{-1} \mathrm{BAP}$ resulted in increment of hydrogen bonded polysaccharide and proteins concentrations, lipid structure and membrane fluidity. Treatments of 2.0 and $4.0 \mathrm{mg} \mathrm{l}^{-1} \mathrm{BAP}$ increased the existence of ferulic acid which also indicates the linkage of xylan and both cellulose and hemicellulose content. There was a significant decrease in the area of the peak which indicated the $\mathrm{C}=\mathrm{O}$ stretching of proteins and pectins for 0.5 and $1.0 \mathrm{mg} \mathrm{l}^{-1} \mathrm{BAP}$ while there was a significant increase for 2.0 and $4.0 \mathrm{mg} \mathrm{l}^{1-1}$ of BAP treatments. The evaluation of molecular data from FT-IR spectroscopy as in the current study might help to estimate different physiological changes at the molecular level in plants depending on plant growth regulator and/or fertilizer applications. Thus, this FT-IR based method can be applied to in vitro propagation studies and also to studies focused on effects of pesticide and/or herbicide applications on plants to understand the metabolic changes in target species.
\end{abstract}

Keywords: Apocynaceae, in vitro multiplication, plant growth regulator, plant primary metabolites, spectroscopy

\section{Introduction}

Plant tissue culture techniques, widely carried out by several researchers, include various methods such as meristem, organ, anther and callus cultures (George, 2008). Their extensive implementations give opportunity for not only in vitro propagation of plants but also for the wide range of application areas such as secondary metabolite production, germplasm conservation and crop improvement. Especially, in vitro propagation studies have been conducted on a variety of species to increase the number of individuals available for ornamental, medicinal or conservational purposes (Viehmannova et al., 2016).

One of the components of plant tissue culture procedures involved in in vitro propagation studies is plant growth regulators (PGRs). Among PGRs, cytokinins are well-known for their role on shoot initiation and multiplication in culture. As 6benzylaminopurine (BAP) is most commonly used as a synthetic cytokinin in plant tissue culture and field studies, its effects have been recognized to provide strategies for the development of reliable and efficient in vitro propagation protocols (Werner $e t$ al., 2001; Wojtania et al., 2015). In a previous study, the impacts of BAP at different concentrations on axillary shoots induction and multiplication of Amsonia orientalis were reported (Acemi $e t$ al., 2013). Costa et al. (2005) found that BAP application reduces rates of chlorophyll degradation in broccoli plant. Furthermore, in Malus domestica, 6-benzylaminopurine treatment caused an increase in flowering rate and stimulation of shoot growth (Li et al., 2015).

The majority of Amsonia species, a member of Apocynaceae (dogbane) family, occur in a wide range of habitats throughout central, southern and eastern North America. A few others are native to southern Europe, Turkey, Japan, Korea and China. Its luscious pale blue flowers make it attractive ornamental variety for many gardeners. A. orientalis Decne. (syn. Rhazya orientalis (Decne.) A. DC.) has a limited natural distribution in the northwest of Turkey and the northeast of Greece. It is, therefore, more familiar to European gardeners than it is to those in the US and the Far East. In the Bern Convention, the European Council placed it on the list of the plant species to be conserved throughout Europe (Bern Convention, 1979). Besides its ornamental properties, $A$. orientalis contains anti-cancer and 
210

anti-tumor properties present in its secondary metabolites, as well as flavonoid glycosides and indole alkaloids (Rahman et al., 1989; Itoh et al., 2002). Even though the plant is limited, the efficacies of its metabolites deserve further exploration (Tutin et al., 1972). In this context, in vitro propagation studies seem to be essential and advantageous to contribute to conservation studies on natural populations of the species and to produce the plant material for medicinal and ornamental purposes.

Most of the in vitro propagation and plant improvement studies aimed to standardize techniques have revealed alterations in morphometric parameters (i.e. mean lengths and numbers of shoots and roots) of the plants in interest. However, only few of them focused on metabolic changes sourced by tested PGRs or fertilizers.

Primary plant metabolites, proteins, lipids, carbohydrates and nucleic acids, are directly involved in growth, development and reproduction. An alteration in the physiology of a plant is determined based upon variance from any difference in conformation, structure and content of these biomolecules. Fourier transform infrared (FT-IR) spectroscopy is a suitable method due to its potential to investigate the structure, function and conformation of biomolecules (Kačuráková et al., 2000; Kačuráková et al., 2002; Alonso-Simon et al., 2011; Turker et al., 2014). By attaining IR spectra from plant samples, it might be possible to detect the minor changes of primary metabolites related to physiological processes (Alonso-Simon et al., 2011; Zhou et al., 2011; Suryawanshi et al., 2015; Renuka et al., 2016). The values of peak positions, bandwidths and peak areas are sensitive to alterations in macromolecules in biological systems. On account of this, the technique has been extensively employed in a variety of research concerned with plants such as evaluation of phytoconstituents (Renuka et al., 2016), monitoring of the modifications in cell wall architecture caused by cellulose biosynthesis inhibitors (Alonso-Simón et al., 2011), the identification of higher plants (Turker et al., 2007) and characterization of plant cell wall carbohydrates (Kačuráková et al., 2000; Kačuráková et al., 2002). However, to the best of our knowledge this method has not been used to evaluate molecular and physiological changes sourced by usage of a cytokinin. Subsequently, by taking the advantages of FT-IR spectroscopy, the current study has aimed to provide information about how BAP treatments altered primary metabolites of $A$. orientalis during in vitro propagation. Since primary metabolites are directly involved in growth and reproduction, any alteration in these essential metabolites would affect survival of the plant. This FT-IR based approach to primary metabolites might help to estimate optimal PGR concentrations to be used in in vitro propagation studies on horticultural and/or threatened plants.

\section{Materials and Methods}

\section{Plant material and disinfection}

Specimens of Amsonia orientalis were collected from its wild population located in, Gaziosmanpaşa district of Balıkesir province of Turkey before flowering. Nodal explants of the specimens were taken as starting plant material for in vitro cultures. All leaves of explants were cut off before they were washed under tap water for $15 \mathrm{~min}$. The explants disinfected by dipping in $70 \%$ ethyl alcohol (EtOH) for 2 min and $1 \%$ sodium hypochlorite $(\mathrm{NaOCl})$ for 10-12 min, respectively and then rinsed in distilled sterile water to remove traces of $\mathrm{NaOCl}$.

\section{Shoot multiplication and nodal culture}

Disinfected single node explants were inoculated vertically in Magenta GA-7 culture vessels $(70 \mathrm{~mm}$ width $\times 70 \mathrm{~mm}$ length $\times$ $100 \mathrm{~mm}$ height) containing $40 \mathrm{ml}$ of Murashige and Skoog's (1962) basal medium (MS) with vitamins. The culture medium was supplemented with $1.0 \mathrm{mg} \mathrm{l}^{-1} \mathrm{BAP}$, and this medium was used to generate the desired number of nodal explants. In the last subculture before main BAP treatments were conducted, explants were cultured in basal MS medium lack of PGRs to stabilize the effects of the previous treatment of BAP. After that, nodal explants were excised from in vitro raised shoots and inoculated into the medium enriched with BAP at different concentrations $\left(0.5,1.0,2.0\right.$ and $\left.4.0 \mathrm{mg} \mathrm{l}^{-1}\right)$. At least 20 nodal explants were employed in each treatment and experiments repeated in three successions. At the end of the incubation period of 4 weeks, leaves of the regenerated shoots were collected for further FT-IR investigation.

\section{Culture medium and conditions}

The medium was supplemented with $30 \mathrm{gl}^{-1}$ sucrose and $7 \mathrm{~g}$ $1^{-1}$ of plant agar (Duchefa, Netherlands). The $\mathrm{pH}$ of the medium was adjusted to 5.7. Cultures were incubated at $23 \pm 1^{\circ} \mathrm{C}$ temperature in a plant growth chamber with a $16 / 8 \mathrm{~h}$ light / dark photoperiod under an illumination of $80 \mu \mathrm{mol} \mathrm{m} \mathrm{m}^{-2}$ photosynthetic photon flux density.

\section{Sample preparation for FT-IR studies}

Leaf samples were dried in a freeze dryer (CHRIST Alpha 12 LD Plus Benchtop Freeze Dry System) overnight and the samples were then ground using agate mortar and pestle. The obtained powder was mixed with dried potassium bromide $(\mathrm{KBr})$ at the ratio of 1:100. The mixture was again dried in the freeze drier for 18 hours to remove all traces of remaining water. Afterwards, it was compressed by a pressure of $\sim 100 \mathrm{~kg} \mathrm{~cm}^{-2}$ (1300 psi) using a hydraulic pellet press to produce a thin $\mathrm{KBr}$ disk.

\section{FT-IRspectroscopic analysis}

Infrared spectra were obtained using a Perkin-Elmer Spectrum One FT-IR spectrometer (Perkin-Elmer Inc., Norwalk, CT, USA) equipped with a Deuterated Triglycine Sulfate (DTGS) detector. Since water and carbon dioxide molecules in the air affect IR spectrum, the spectra of both were recorded together as background and subtracted automatically by using appropriate software (Perkin Elmer Spectrum One software).

The spectra of samples were recorded in the $4000-400 \mathrm{~cm}^{-1}$ region at room temperature. Each interferogram was collected with 100 scans at $4 \mathrm{~cm}^{-1}$ resolution. Each sample was scanned under the same conditions with three different pellets, all of which gave identical spectra. Three replicates were averaged and the final spectra were used in detailed data analysis and statistical analysis.

The data analysis and manipulations were carried out using the same software. The spectra were first smoothed with nineteen-point Savitsky-Golay smooth function (Turker $e t$ al., 2007) to remove the noise. The band positions were measured using the frequency corresponding to the center of weight (80\%). 
Band areas were calculated from smoothed and baseline corrected spectra using Spectrum One software. The bandwidth values of specific bands were calculated as the width at $0.80 \times$ height of the signal in terms of $\mathrm{cm}^{-1}$. In order for the visual demonstration of spectral alterations, the spectra were baseline corrected and normalized with respect to specific bands for visual demonstration in order to allow a point-to-point comparison (Turker et al., 2007; Severcan et al., 2010; Ozek et al., 2014; Turker et al., 2014).

\section{Statistical analysis}

FT-IR results were expressed as 'mean \pm standard error (SE)'. By performing the software IBM SPSS Statistics 19, FT-IR data were compared and statistically analyzed using ANOVA.

\section{Results and Discussion}

By monitoring the variations in the frequencies, bandwidths and peak areas of the vibrational modes from primary metabolites of $A$. orientalis spectral investigation revealed that there were prominent variations treated groups compared to control one. Fig. 1 and 2 show normalized infrared spectra of 0.5 , $1.0,2.0$ and $4.0 \mathrm{mgl}^{-1}$ concentrations of BAP in $3050-2800 \mathrm{~cm}^{-1}$ and $2050-870 \mathrm{~cm}^{-1}$ region, respectively.

The spectral bands were assigned in detail based upon the literature and were represented in Table 1 . The results of detailed analysis of some modes (frequency and band area values) were presented in Table 2.

The first peak located at $3414 \mathrm{~cm}^{-1}$ arised from the stretching of the $\mathrm{N}-\mathrm{H}$ and the $\mathrm{O}-\mathrm{H}$ molecules present in proteins and carbohydrates (data not shown). Water molecules were reported to have also impact on this peak (Turker et al., 2007; Turker $e t$ al., 2014). Yet, as mentioned in Material and Methods part, the samples were completely dried and thus water was largely taken out during sample preparation. As a result, the contribution of water molecules on this peak could be neglected and only the input of proteins and carbohydrates can be concerned. As shown in Table 2, the area of this band is increased for all treated groups, but it is significant only for $2 \mathrm{mgl}^{-1}$. This might be resulted from an increment in the concentration of polysaccharides and

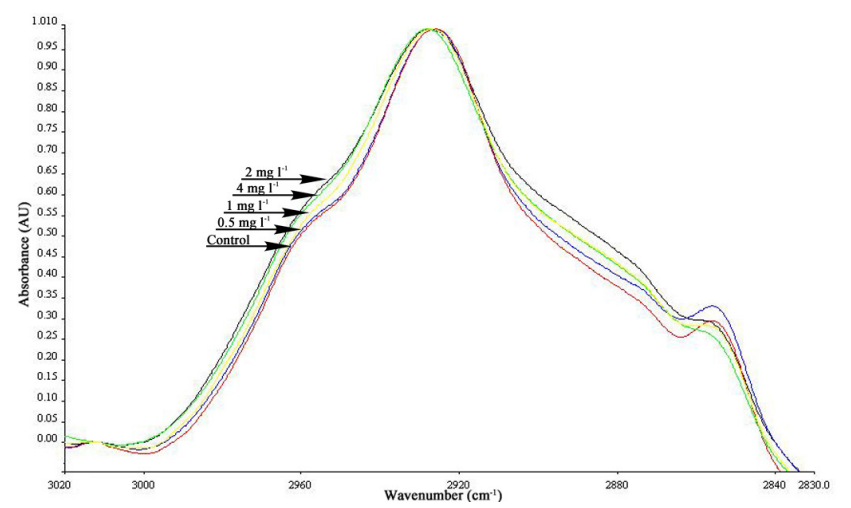

Fig. 1. Representative FT-IR spectra of control, 0.5, 1.0, 2.0 and $4.0 \mathrm{mg} \mathrm{l}^{-1}$ of BAP in the region of $3050-2800 \mathrm{~cm}^{-1}$. The spectra were normalized with respect to the $\mathrm{CH}_{2}$ asymmetric stretching at $2925 \mathrm{~cm}^{-1}$. (Red line Control; blue line 0.5; yellow line 1.0; black line 2.0; green line $4.0 \mathrm{mg} \mathrm{l}^{-1}$ of BAP) proteins containing $\mathrm{N}-\mathrm{H}$ and $\mathrm{O}-\mathrm{H}$ molecules (Yang and Yen, 2002; Toyran et al., 2004; Suryawanshi et al., 2015).

Besides, the broadness of this mode is associated with the extent of hydrogen bonding in proteins and polysaccharides (Dalvi et al., 2000; Turker et al., 2007; Turker et al., 2014). The finding of a rising area of the peak might mean that BAP treatment with all concentrations led to an increase in proteins and carbohydrates together with high hydrogen capacity. On the contrary, it is known that plant cells can increase in size by enhancing cell volume due to intracellular vacuole expansion. This is achieved by uptake of water, which may cause hydrogen bond formation between the related biomolecules. According to our data, $2.0 \mathrm{mgl}^{-1}$ concentration of BAP has the most capability to provoke rising the concentration of hydrogen bonded proteins and carbohydrates, which may be an indication of cell growth and cell wall expansion.

The region covering $3050-2800 \mathrm{~cm}^{-1}$ includes the absorption attributed to the $\mathrm{CH}_{2}$ asymmetric stretching vibration $\left(2925 \mathrm{~cm}^{-1}\right)$ associated with the degree of the membrane order. The frequency shifting of the peak can be used to monitor trans/gauche isomerization in the system and it increases with the introduction of trans conformers in the fatty acyl chains (Melin et al., 2000; Akkas et al., 2007; Turker et al., 2016). The frequency of $\mathrm{CH}_{2}$ asymmetric stretching band significantly shifted to higher frequency values only for $2.0 \mathrm{mgl}^{-1}$ concentration. This variation to higher values for this concentration demonstrates an increase in the disorder of the system, which suggests an increment in the number of gauche conformers resulting in less rigid membranes. The concentration dependent effect of BAP on lipid order might reveal altered lipid structure along with the formation of cross-linked lipid-protein moieties (Akkas et al., 2007; Turker et al., 2014; Turker et al., 2016). The superiority of $2.0 \mathrm{mgl}^{-1} \mathrm{BAP}$ on lipid structure might represent the most pronounced response of the plant to this concentration. This event might also refer to the modification of membrane lipid structure upon activation of membrane-located proteins such as histidine kinases (Choi et al., 2012), which perceived $2.0 \mathrm{mg} \mathrm{l}^{-1}$ of BAP. On the other hand, it should be mentioned that the monitoring of activity of membrane proteins is a complex task since they are embedded into the lipid bilayer of the membrane as well as they tend to be unstable when extracted

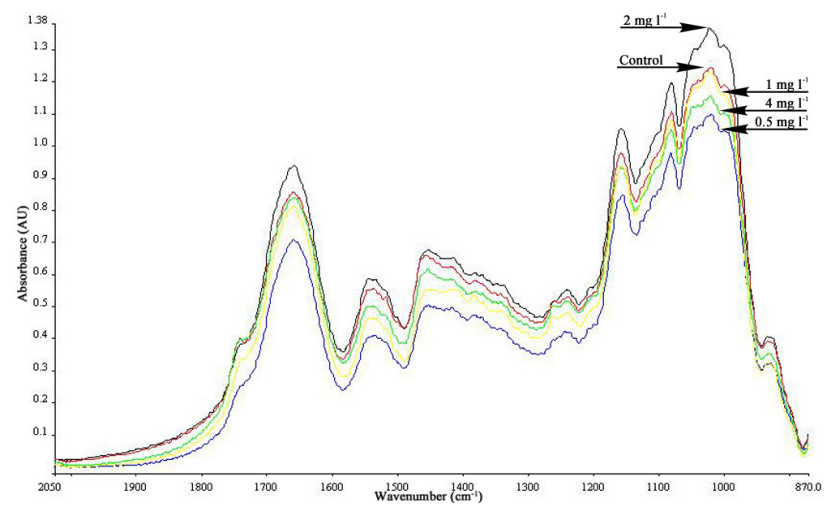

Fig. 2. Representative FT-IR spectra of control, 0.5, 1.0, 2.0 and $4.0 \mathrm{mg} \mathrm{l}^{-1}$ of BAP in the region of $2050-870 \mathrm{~cm}^{-1}$. The spectra were normalized with respect to the Amide I at 1653 $\mathrm{cm}^{-1}$. (Red line Control; blue line 0.5; yellow line 1.0; black line 2.0; green line $4.0 \mathrm{mg} \mathrm{l}^{-1}$ of BAP) 
Table 1. General band assignments of average FT-IR spectrum of Amsonia orientalis based on the literature (Turker $e$ t al., 2007; Renuka et al., 2016)

\begin{tabular}{ll}
\hline Wavenumber $\left(\mathrm{cm}^{-1}\right)$ & Definition of the Spectral Assignments \\
\hline 3414 & Amide A: proteins and polysaccharides \\
2925 & $\mathrm{CH}$ symmetric stretching: mainly lipids, with a little contribution from proteins \\
1732 & $\mathrm{C}=\mathrm{O}$ stretch: phenolic esters, lipids, xylan and hemicellulose \\
1653 & Amide I (mainly C=O stretch): proteins and pectins \\
1030 & C-O-C stretching: cellulose and hemicellulose \\
\hline
\end{tabular}

Table 2. The frequency and peak area values of FT-IR bands for control, and different concentrations of BAP for Amsonia orientalis. Data represented average \pm SE of three replicates, each with at least 20 explants (BAP: 6-benzylaminopurine)

\begin{tabular}{|c|c|c|c|c|c|}
\hline Functional group & Control & $0.5 \mathrm{mg} \mathrm{l}^{-1} \mathrm{BAP}$ & $1.0 \mathrm{mg} \mathrm{l}^{-1} \mathrm{BAP}$ & $2.0 \mathrm{mg} \mathrm{l}^{-1} \mathrm{BAP}$ & $4.0 \mathrm{mg} \mathrm{l}^{-1} \mathrm{BAP}$ \\
\hline & \multicolumn{5}{|c|}{ Frequency values } \\
\hline \multirow[t]{2}{*}{$\mathrm{CH}_{2}$ asymmetric } & $2923.44 \pm 0.70$ & $2925.66 \pm 0.08$ & $2924.42 \pm 1.56$ & $2926.01 \pm 0.13^{*}$ & $2925.17 \pm 0.95$ \\
\hline & \multicolumn{5}{|c|}{ Band area values } \\
\hline $\mathrm{N}-\mathrm{H}$ O-H stretching & $0.86 \pm 0.19$ & $0.88 \pm 0.27$ & $0.87 \pm 0.04$ & $0.92 \pm 0.06^{*}$ & $0.87 \pm 0.31$ \\
\hline $\mathrm{CH}_{2}$ asymmetric & $0.39 \pm 0.08$ & $0.44 \pm 0.09^{*}$ & $0.45 \pm 0.16^{*}$ & $0.49 \pm 0.13^{* *}$ & $0.42 \pm 0.18^{*}$ \\
\hline $\mathrm{C}=\mathrm{O}$ stretching $\left(1653 \mathrm{~cm}^{-1}\right)$ & $0.60 \pm 0.17$ & $0.57 \pm 0.08^{*}$ & $0.56 \pm 0.18^{*}$ & $0.62 \pm 0.09^{*}$ & $0.63 \pm 0.10^{*}$ \\
\hline $\mathrm{C}=\mathrm{O}$ stretching $\left(1732 \mathrm{~cm}^{-1}\right)$ & $0.24 \pm 0.05$ & $0.25 \pm 0.02$ & $0.26 \pm 0.08$ & $0.37 \pm 0.04^{*}$ & $0.33 \pm 0.01^{*}$ \\
\hline \multirow[t]{2}{*}{$\mathrm{C}-\mathrm{O}-\mathrm{C}$ stretching } & $0.52 \pm 0.15$ & $0.53 \pm 0.14$ & $0.53 \pm 0.20$ & $0.58 \pm 0.07^{*}$ & $0.59 \pm 0.13^{*}$ \\
\hline & \multicolumn{5}{|c|}{ Bandwidth values } \\
\hline $\mathrm{CH}_{2}$ asymmetric & $12.11 \pm 0.06$ & $12.09 \pm 0.07$ & $12.00 \pm 0.19$ & $13.98 \pm 0.27^{*}$ & $12.33 \pm 0.07$ \\
\hline
\end{tabular}

from their native environment. In order to account for this issue, we have alternatively analyzed the band area of the $\mathrm{CH}_{2}$ asymmetric stretching mode. The dramatic increment in area by application of $2.0 \mathrm{mgl}^{-1} \mathrm{BAP}$ might elicit longer chain lengths of fatty acids, which in turn, altered lipid composition and lipid distribution, as well. This may further stimulate alteration membrane thickness, which may provoke variations in membrane fluidity (Toyran et al., 2004; Turker et al., 2007; Turker et al., 2014; Turker et al., 2016). To confirm this, we have also measured the bandwidth value of the mode. The highest increase in this value for $2.0 \mathrm{mg} \mathrm{l}^{-1}$ among the applied concentrations of BAP reflects a more fluid membrane (Yang and Yen, 2002; Cakmak et al., 2011). It has been reported by Los et al. (2013) that changes in membrane fluidity leads to activity changes or activation of membrane-bound enzymes, ion channels, and receptors. From this point, a more fluid membrane may further represent a high degree of cellular activation upon $2.0 \mathrm{mgl}^{-1} \mathrm{BAP}$, too. With the obtained data of the current study related to the membrane order and membrane fluidity, we could acquire information about the activity of membrane-located proteins upon BAP treatment without isolating them.

The mode arisen at $1732 \mathrm{~cm}^{-1}$ is assigned to the phenolic ester (Alonso-Simón et al., 2011), lipids (Turker et al., 2007) and ferulic acid (Kačuráková et al., 1999). Although its peak area value was slightly increased for both $0.5 \mathrm{mg} \mathrm{l}^{-1}$ and $1 \mathrm{mg} \mathrm{l}^{-1}$ concentrations, a significant increase of this value for $2.0 \mathrm{mg} \mathrm{l}^{-1}$ and $4.0 \mathrm{mg} \mathrm{l}^{-1}$ was obtained. It has been stated that xylans are closely associated with covalent and other links with other plant cell wall constituents, such as lignin, protein, and pectic polysaccharides. The functional properties of these molecules may be affected by the presence of minor amounts of phenolics (Peaucelle et al., 2012) which couple with polysaccharide chains through ferulic acid dimers. These are partly responsible for the insolubility of annual plant heteroxylans (Saulnier et al., 1995). The increase of this mode for 2.0 and $4.0 \mathrm{mg} \mathrm{l}^{-1} \mathrm{BAP}$ might suggest the existence of ferulic acid which also indicates the linkage of xylan with other biomolecules mentioned above. The incidence of ferulic acid might give rise to low $\mathrm{pH}$, which was also suggested to show expansion of the cell wall (Rayle and Cleland, 1992). As illustrated in Table 1 , this mode is also attributed to hemicellulose (Kačuráková et al., 2000; Turker et al., 2007; Zhou et al., 2011; Suryawanshi et al., 2015). According to the literature, growing plant cell structure stimulates cellulose to hemicellulose conversion in order to promote rapid enlargement. This enables the cell wall to get more flexible to expand and the increase in the peak may further demonstrate the conversion of hemicellulose from cellulose during cell growth. The mode at $1030 \mathrm{~cm}^{-1}$ is from cellulose and hemicellulose (Kačuráková et al., 2000; Hori and Sugiyama, 2003; Turker et al., 2007; Zhou et al., 2011; Suryawanshi et al., 2015). For 2.0 and $4.0 \mathrm{mg} \mathrm{l}^{-1} \mathrm{BAP}$ treatments an increase in the peak area was found, which might elicit significant increase in both cellulose and hemicellulose content. But, as mentioned before, the incident of hemicellulose is expected during cell growth brought about conversion from cellulose. The obvious increase in the peak $\left(1030 \mathrm{~cm}^{-1}\right)$ might be resulted from hemicellulose rather than cellulose, as also obtained from the $\mathrm{C}=\mathrm{O}$ stretching mode at $1732 \mathrm{~cm}^{-1}$. Similarly, the increment in the $\mathrm{C}=\mathrm{O}$ stretching proves the existence of phenolic ester at higher degree for 2.0 and $4.0 \mathrm{mg} \mathrm{t}^{-1}$ concentrations of BAP. The incidence of phenolic compounds might be resulted due to the rich secondary metabolite content of the plant of which have anticancer and antitumor effects. These kinds of chemicals have been previously detected, isolated and characterized by different techniques such as HPLC and NMR (Rahman et al., 1989). It should be noted that these procedures are time-consuming, expensive and labor intensive. In contrast to this, although FT-IR spectroscopy offers relative information, it can be proposed as easier and rapid approach to detect the presence of these chemicals in the system. Furthermore, it can also be carried out on the optimization processes of the cell cultures to determine the desired chemicals.

The band located around $1653 \mathrm{~cm}^{-1}$ is arisen from the $\mathrm{C}=\mathrm{O}$ stretching of proteins and pectins (Akkas et al., 2007; Turker $e t$ al., 2007; Turker et al., 2014; Turker et al., 2016). As illustrated in Table 2, there was a significant decrease in the area of the peak for 0.5 and $1.0 \mathrm{mgl}^{-1}$ while there was a significant increase for 2.0 and $4.0 \mathrm{mg} \mathrm{l}^{-1}$ of BAP. The increment in the area might reveal 
high protein content (Turker et al., 2014; Renuka et al., 2016), potentially due to an accumulation and upregulation of various proteins. Here, it should be mentioned that FT-IR spectroscopy cannot distinguish specific proteins, but only information concerning entire protein profile of $A$. orientalis including extracellular, plasma membrane, cytoplasm and nuclear proteins. However, the increase in Amide I mode could be assigned to the high content of some proteins depending on the literature. This might be resulted from action of cytokinins which are known by their stimulatory effects on protein synthesis. For instance, metatopolin, a type of cytokinin, induces certain proteins in cultured radish (Raphanus sativus) cotyledones (Çağ and Palavan-Ünsal, 2003). Additionally, as a confirming issue, binding of cytokinin to its receptors results in a phosphorylation cascade, which in turn, activates type B Arabidopsis response regulators (ARRs) and inactivates transcription factors under normal conditions (Hwang and Sheen, 2001; Kakimoto, 2003). Furthermore, the proteins called expansins are minor components of plant cell wall. As proposed by Cosgrove $(2000,2015)$, they are responsible for loosening the structure of the wall when a cell grows. These proteins weaken non-covalent binding between cell wall polysaccharides, thereby allowing the cell to enlarge rapidly. Considering of BAP being a cytokinin, our result is in accordance with the literature stating that cytokinins promote synthesis of certain proteins such as ARRs (Hwang and Sheen, 2001; Argyros et al., 2008) and expansins. On the other hand, pectin molecule contributes to this mode (Turker et al., 2007; Alonso-Simon et al., 2011). The same trend is valid for pectin increment in the system directly owing to the production of high degree of pectin polysaccharides. It is known that during plant cell growth for the preparation of mitotic division, middle lamella is formed, thereby generating pectic substances (Evert and Eichhorn, 2005), which was found the highest ratio for 2.0 and $4.0 \mathrm{mgl}^{-1}$ concentration.

Consequently, studies performed for in vitro propagation protocols and improvement of food/crop plants have been generally based on measuring morphometric parameters under the influences of several internal and/or external factors such as hormone levels, temperature, light intensity or relative humidity that may further bring about the discrepancy. It means that the data depending on only morphometric parameters of the propagated plant may not reflect the actual circumstances at molecular level. The evaluation of molecular data such as the obtained ones from FT-IR spectroscopy as in the current study might help to estimate the some physiological changes at molecular level in plants due to PGR and/or fertilizer applications. Thus, FT-IR based this method can be applied to in vitro propagation and also to studies focused on effects of pesticide and/or herbicide applications on plants to understand the metabolic changes in target species.

\section{Acknowledgments}

We are very grateful to Francis Quattrone and Seda Yazıcı for editing the language of the manuscript.

\section{References}

Acemi A, Özen F, Kuran R (2013). In vitro propagation of Amsonia orientalis Decne. from nodal segments of adult plants. Propagation of Ornamental Plants 13(1):25-32.
Akkas SB, Inci S, Zorlu F, Severcan F (2007). Melatonin affects the order, dynamics and hydration of brain membrane lipids. Journal of Molecular Structure 834836:207-215.

Alonso-Simón A, Garcia-Angula P, Melida H, Encina A, Alvarez J, Acebes J (2011). The use of FTIR spectroscopy to monitor modifications in plant cell wall architecture caused by cellulose biosynthesis inhibitors. Plant Signal Behavior 6(8):11041110.

Argyros RD, Mathews DE, Chiang YH, Palmer CM, Thibault DM, Etheridge N,... Schaller GE (2008). Type B response regulators of Arabidopsis play key roles in cytokinin signaling and plant development. Plant Cell 20:2102-2116.

Bern Convention (1979). Convention on the conservation of European wildlife and natural habitats. Retrieved 2015 Oct 03 from https://rm.coe.int/CoERMPublicCommonSearchServices/DisplayD CTMContent?documentId=0900001680304354.

Cakmak G,Zorlu F, Severcan M, Severcan F (2011). Screening of protective effect of amifostine on radiation-induced structural and functional variations in rat liver microsomal membranes by FT-IR spectroscopy. Analytical Chemistry 83:2438-2444.

Choi J, Lee J, Kim K, Cho M, Ryu H, An G, Hwang I (2012). Functional identification of $\mathrm{OsH} \mathrm{H} 6$ as a homotypic cytokinin receptor in rice with preferential affinity for iP. Plant and Cell Physiology 53:1334-1343.

Cosgrove DJ (2000) Loosening of plant cell walls by expansins. Nature 407:321-329.

Cosgrove DJ (2015). Plant expansins: diversity and interactions with plant cell walls. Current Opinion in Plant Biology 25:162-172.

Costa ML, Civello PM, Chaves AR, Martínez GA (2005). Effect of ethephon and 6-benzylaminopurine on chlorophyll degrading enzymes and a peroxidase-linked chlorophyll bleaching during post-harvest senescence of broccoli (Brassica oleracea $\mathrm{L}$.) at $20^{\circ} \mathrm{C}$. Postharvest Biology and Technology 35(2):191-199.

Çağ S, Palavan-Ünsal N (2003). The effect of meta-topolin on protein profile in radish cotyledons. Journal of Cell and Molecular Biology 2:3134.

Dalvi A, Al-Rasheed R, Javeed M (2000). Studies on organic foulants in the seawater feed of reverse osmosis plants of SWCC. Desalination 132:217-224.

Evert RF, Eichhorn SE (2005). Raven Biology of plants. Freeman WH and Company,New York.

George EF (2008). Plant propagation by tissue culture. Springer (3rd ed) Dordrecht.

Hori R, Sugiyama JA (2003). Combined FT-IR microscopy and principal component analysis on softwood cell walls. Carbohydrate Polymers 52:449-453.

Hwang I, Sheen J (2001). Two-component circuitry in Arabidopsis cytokinin signal transduction. Nature 413:383-389.

Itoh A, Kumashiro T, Tanahashi T, Nagakura N, Nishi T (2002). Flavonoid gycosides from Rhazya orientalis. Journal of Natural Products 65:352-357.

Kačuráková M, Wellner N, Ebringerova A, Hromádková Z, Wilson RH, Belton PS (1999). Characterization of xylan-type polysaccharides and associated cell wall components by FT-IR and FT-Raman spectroscopies. Food Hydrocolloids 13:35-41. 
214

Kačuráková M, Capeka P, Sasinkova V, Wellner N, Ebringerová A (2000). FT-IR study of plant cell wall model compounds: pectic polysaccharides and hemicelluloses. Carbohydrate Polymers 43:195-203.

Kačuráková M, Smith AC, Gidley MJ, Wilson R (2002). Molecular interactions in bacterial cellulose composites studied by $1 \mathrm{D}$ FT-IR and dynamic 2D FT-IR spectroscopy. Carbohydrate Research 337:11451153.

Kakimoto T (2003). Biosynthesis of cytokinins. Journal of Plant Research 116:233-239.

Li Y, Zhang D, Xing L, Zhang S, Zhao C, Han M (2015). Effect of exogenous 6-benzylaminopurine (6-BA) on branch type, floral induction and initiation, and related gene expression in 'Fuji' apple (Malus domestica Borkh). Plant Growth Regulation 79(1):65-70.

Los DA, Mironov KS, Allakhverdiev SI (2013). Regulatory role of membrane fluidity in gene expression and physiological functions. Photosynthesis Research 116:489-509.

Melin A, Perromat A, Deleris G (2000). Pharmacologic application of Fourier transform IR spectroscopy: in vivo toxicity of carbon tetrachloride on rat liver. Biopolymers 57:160-165.

Murashige T, Skoog F (1962). A revised medium for rapid growth and bioassays with tobacco tissue cultures. Physiologia Plantarum 15:473497.

Ozek N, Bal I, Sara Y, Onur R, Severcan F (2014). Structural and functional characterization of simvastatin-induced myotoxicity in different skeletal muscles. Biochimica et Biophysica Acta 1840:406-415.

Peaucelle A, Braybrook S, Höfte H (2012). Cell wall mechanics and growth control in plants: the role of pectins revisited. Frontiers in Plant Science 3(121):1-6.

Rahman AU, Qureshi MM, Zaman K, Malik S, Ali SS (1989). The alkaloids of Rhazya stricta and $R$ orientalis - a review. Fitoterapia 60(4):291-322.

Rayle D, Cleland R (1992). The acid growth theory of auxin-induced cell elongation is alive and well. Plant Physiology 99:1271-1274.

Renuka B, Sanjeev B, Ranganathan D (2016). Evaluation of phytoconstituents of Caralluma nilagirina by FTIR and UV-Vis spectroscopic analysis. Journal of Pharmacognosy and Phytochemistry 5(2):105-108.

Saulnier L, Vigouroux J, Thibault F (1995). Isolation and partial characterization of feruloylated oligosaccharides from maize bran. Carbohydrate Research 272:241-253.

Severcan F, Bozkurt O, Gurbanov R, Gorgulu G (2010). FT-IR spectroscopy in diagnosis of diabetes in rat animal model. Journal of Biophotonics 3:621-631.
Suryawanshi A, Bhise R, Suryawanshi D (2015). Study of nutrient stresses in plants by FTIR spectroscopy. International Journal of Chemical and Physical Sciences 4:35-39.

Toyran N, Zorlu F, Donmez G, Oge K, Severcan F (2004). Chronic hypoperfusion alters the content and structure of proteins and lipids of rat brain homogenates: a Fourier transform infrared spectroscopy study. European Biophysics Journal 33:549-560.

Turker S, Dogan M, Severcan F (2007). The characterization and differentiation of higher plants by Fourier transform infrared spectroscopy. Applied Spectroscopy 61:300-308.

Turker S, Ilbay G, Severcan M, Severcan F (2014). Investigation of compositional, structural, and dynamical changes of pentylenetetrazolinduced seizures on a rat brain by FT-IR spectroscopy. Analytical Chemistry 86:1395-1403.

Turker KS, Mutlu O, Celikyurt I, Akar F, Ulak G (2016). Tianeptine, olanzapine and fluoxetine show similar restoring effects on stress induced molecular changes in mice brain: An FT-IR study. Spectrochimica Acta Part A: Molecular and Biomolecular Spectroscopy 161:178-185.

Tutin TG, Heywood VH, Burges NA, Moore DM, Valentine DH, Walters SM, Webb DA (1972). Flora Europaea vol 3. Diapensiaceae to Myoporaceae. Cambridge University Press, Cambridge.

Werner T, Motyka V, Strnad M, Schmülling T (2001). Regulation of plant growth by cytokinin. Proceedings of the National Academy of Sciences of the United States of America 98:10489-10492.

Wojtania A, Skrzypek E, Gabryszewska (2015). Effect of cytokinin, sucrose and nitrogen salts concentraions on the growth and development and phenolic content in Magnolia soulangiana Coates shoots in vitro. Acta Scientiarum Polonorum Hortorum Cultus 14(3):51-62.

Viehmannova I, Cepkova PH, Vitamvas J, Streblova P, Kisilova J (2016). Micropropagation of a giant ornamental bromeliad Puya berteroniana through adventitious shoots and assessment of their genetic stability through ISSR primers and flow cytometry. Plant Cell, Tissue and Organ Culture 125: 293-302.

Yang J, Yen E (2002). Early salt stress effects on the changes in chemical composition in leaves of ice plant and Arabidopsis. A Fourier transform infrared spectroscopy study. Plant Physiology 130:1032-1040.

Zhou G, Taylor G, Polle A (2011). FTIR-ATR-based prediction and modelling of lignin and energy contents reveals independent intraspecific variation of these traits in bioenergy poplar. Plant Methods 7:1219. 